\title{
Subungual extra skeletal chondroma with toe nail deformity: case report
}

\begin{abstract}
Extraskeletal Chondroma is a rare tumor which occurs frequently in hands and feet. It's histology shows mature hyaline cartilage which is arranged in distinct lobules with fibrosis, or ossification, or myxoid areas. ESCs may recur locally but they never metastasize, which require removing the tumor completely, including the capsular structure and adhesion sites. We are reporting a case of extraskeletal chondroma which was located in the subungual right great toe in a 30-year-old male patient surgically treated. The histopathology in our case showed features of extraskeletal chondroma. So far there has been no recurrence of the tumor.
\end{abstract}

Keywords: extraskeletal chondroma, cartilaginous tumor, soft tissue, subungual toe, unusual location
Volume 2 Issue I - 2018

\section{Salim Gallouj, Niema Aqil, Fatima Zahra Mernissi}

Department of dermatology, University Hospital Center Hassan II, Morocco

Correspondence: Niema Aqil, Department of dermatology, University Hospital Center Hassan II, Fez, Morocco, Tel: 00212661328727; E-mail niemaaqil90@gmail.com

Received: January 23, 2018| Published: February 16, 2018

\section{Introduction}

Extraskeletal chondroma (ESC) is a rare, benign, cartilaginous tumor that develops in soft tissues and is not attached to the periosteum or bone cortex. ${ }^{1}$ In this article, we are reporting a case of ESC which was located in the subungual right great toe in a 30-year-old male patient surgically treated.

\section{Case presentation}

A 30-year-old patient was seen in January 2017 because of a pink, hard nodule partly covered by whitish hyperkeratotic scales appearing beneath the nail of the right great toe (Figure 1). The nodule that caused the lifting of the distal part of the nail plate had been aching when she bumped accidentally. The patient denied any preceding trauma. The dermoscopy revealed the presence of yellowish-white scales and arborisants vessels resting on a red-milky background (Figure 2). The suspected diagnoses were exostosis, achromic melanoma, cutaneous metastasis, squamous cell carcinoma, or sarcoma. X-ray examination revealed only slight modifications of bony outline with thinning of cortex, without subungual exostosis. The tumor was radiolucent (Figure 3). Since no obvious malignant findings such as bone destruction or invasion were obtained by imaging, the tumor was considered benign. A tumor biopsy was performed under local anesthesia, aimed at establishing a histological diagnosis. Histopathological examination of the specimen revealed the presence of mature hyaline cartilage, with a relatively low cell density and small mononuclear chondrocytes with no apparent atypia in the cartilage space. Subsequently, the tumor was resected and the pathological study showed the presence of tumor proliferation made of mature cartilaginous lobules with regular chondrocytes (Figures 4 $\&$ 5). Therefore, the final diagnosis was determined as extraskeletal chondroma. So far there has been no recurrence of the tumor (Figure $6)$.

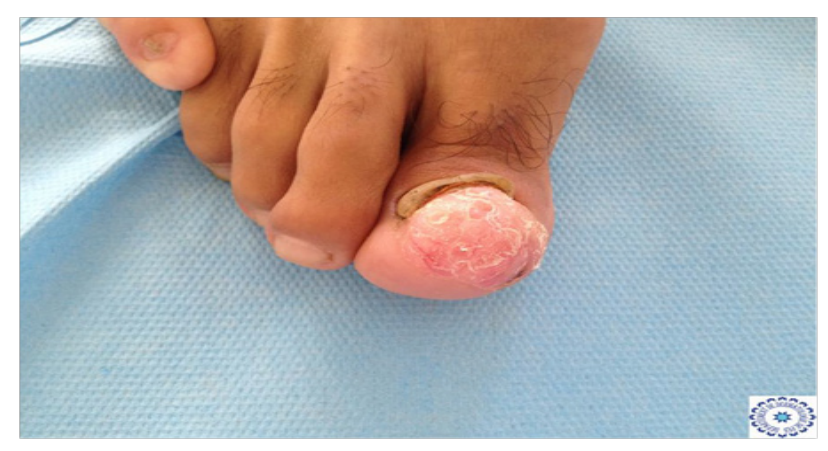

Figure I Pink nodule covered by whitish hyperkeratotic scales appearing beneath the nail of the right great toe.

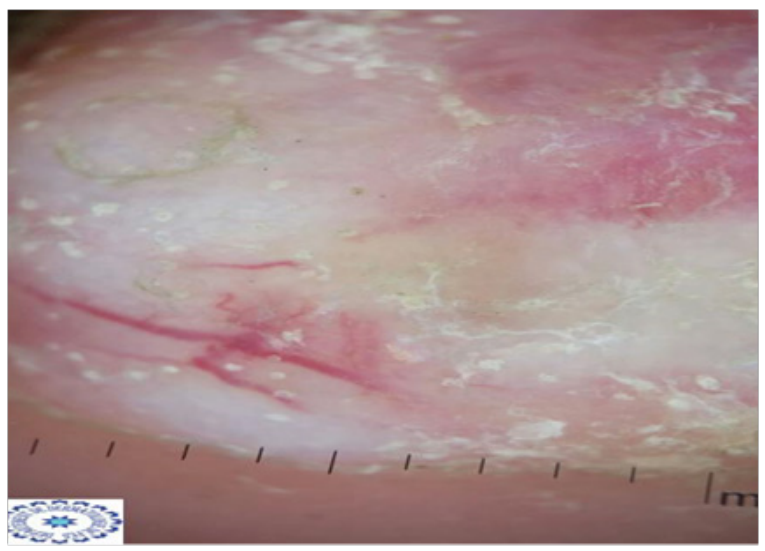

Figure 2 Dermoscopy revealed the presence of yellowish-white scales and arborisants vessels resting on a red-milky background. 


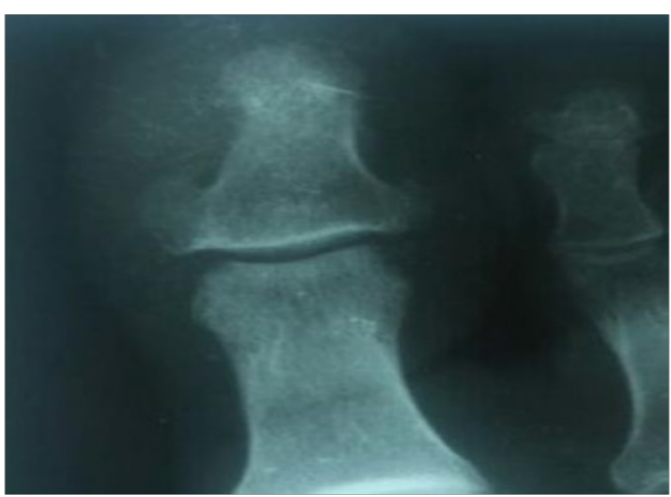

Figure 3 X-ray examination revealed only slight modifications of bony outline with thinning of cortex.

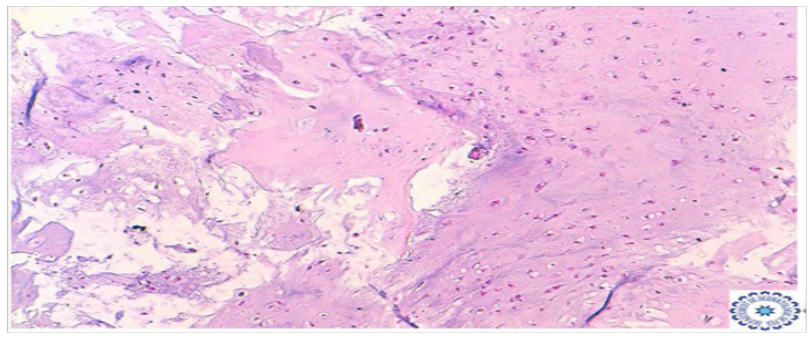

Figure 4 Photomicrograph showing tumor proliferation made of mature cartilaginous lobules with regular chondrocytes $(\mathrm{H}$ and $\mathrm{E})$.

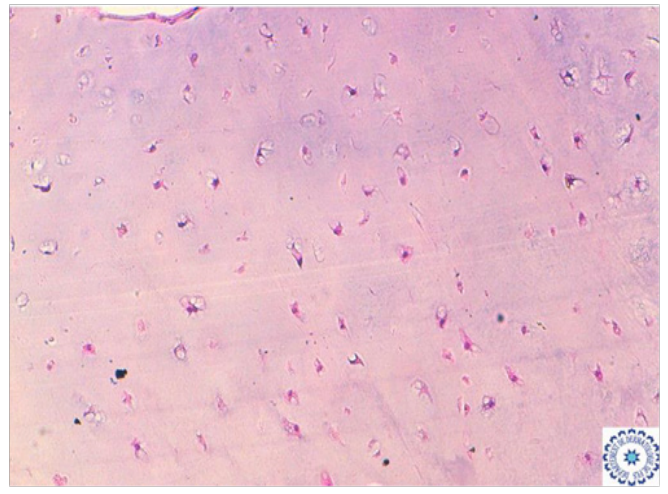

Figure 5 Photomicrograph showing regular chondrocytes ( $\mathrm{H}$ and $\mathrm{E})$.

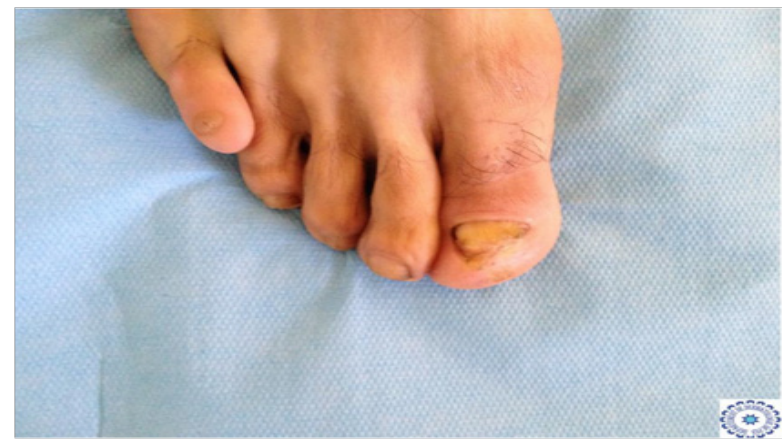

Figure 6 Clinical appearance 7 months after surgery.

\section{Discussion}

The extraskeletal chondroma is rare relative to the other soft tumor, and about 200 cases have been reported in the English literature., ${ }^{1,2}$ The most common sites of occurrence are the hands, with more than $60 \%$ of all extraskeletal chondromas located here. ${ }^{2-4}$ Occurrence in the fingers has been reported in more than $60 \%$ of the hands, most of which have occurred on the palmar side..$^{5-10}$

Because extraskeletal chondroma is a nodular mass that grows slowly in soft tissue without any continuity with the bone, there are few symptoms and the preoperative duration of symptoms tends to be long. Until now, we are aware of only 6 case reports that describe an extraskeletal chondroma of subungual origin and each had a mild nail deformity. ${ }^{11-16}$ The present case had a severe nail deformity. This created difficulty in diagnosing the extraskeletal chondroma because it grew slowly in the subungual region with few characteristic findings. The radiological appearance of the extraosseous chondroma varies with the extent of calcification and the reaction of adjacent tissues. A calcification focus develops in about one-third of cases, usually at the center of the lesion. ${ }^{1-3,17}$ Diffuse calcification may occur at a late stage, making it difficult to demonstrate the cartilaginous nature of the tumor. ${ }^{17}$ Bone lesions are rare, although the mass may be responsible for erosions or cortical changes as in our patient.

Histopathologically, most extraskeletal chondromas show lobulated mature hyaline cartilage tissue accompanied by myxoid degeneration, ossification, and calcification. The others (approximately 15\%) show atypical features that should be differentiated from chondrosarcoma. The findings accompany increased cellularity, nuclear pleomorphism, the presence of chondroblastic cells and epithelioid cells, and the proliferation of multinucleated giant cells. ${ }^{2,3}$

The presence of cosmetic problems such as nail deformation or symptoms such as pain is considered a primary indication for surgical removal. Because the incidence of local recurrence after simple removal of the tumor itself is reported to be $17 \%,{ }^{11}$ it is advisable to remove the tumor completely, including the capsular structure and adhesion sites.

\section{Patient consent form}

Patient consent related case report take the permission from concerned patient.

\section{Acknowledgements}

None.

\section{Conflict of interest}

The author declares no conflicts of interest.

\section{References}

1. Dahlin DC, Salvador AH. Cartilaginous tumors of the soft tissues of the hands and feet. Mayo Clin Proc. 1974;49(10):721-726.

2. Chung EB, Enzinger FM. Chondroma of soft parts. Cancer. 1978;41(4):1414-1424.

3. Weiss SW, Goldblum JR. Cartilaginous soft tissue tumors. In: Weiss SW, Goldblum JR, editors. Enzinger and Weiss's soft tissue tumors. 4th ed. USA; 2001. 
4. Fletcher CD, Krausz T. Cartilaginous tumours of soft tissue. Appl Pathol. 1988;6(3):208-220.

5. Strong ML Jr. Chondromas of the tendon sheath of the hand: report of a case and review of the literature. J Bone Joint Surg Am. 1975;57(8):1164 1165 .

6. Mahoney JL. Soft tissue chondromas in the hand. J Hand Surg Am 1987;12(2):317-320.

7. DelSignore JL, Torre BA, Miller RJ. Extraskeletal chondroma of the hand: case report and review of the literature. Clin Orthop Relat Res. 1990;254:147-152.

8. Uchinuma E, Kimata S, Yamashita R, et al. Extraskeletal chondroma with bony destruction: a case report and review of literature. Eur J Plast Surg. 1994;17(3):159-160.

9. Folsom GJ, Lee DH, Lopez-Ben R, et al. Hand mass in a 15-year-old boy. Clinical Orthopaedics \& Related Research. 2003;412:269-275.

10. Singh P, Mathur SK, Kundu ZS, et al. Extraskeletal chondroma of the hand: a case report. Indian J Pathol Microbiol. 2005;48(2):206-208.
11. Ayala F, Lembo G, Montesano M. A rare tumor: subungual chondroma. Report of a case. Dermatologica. 1983;167(6):339-340.

12. Bauer HI, Kaatz M, Kluge WH, et al. Subungual chondroma, a case report. Z Rheumatol. 2002;61(1):58-61.

13. Cho SB, Kim SC. Subungual extraskeletal chondroma mimicking glomus tumor. J Dermatol. 2003;30(6):492-494.

14. Ishii T, Ikeda M, Oka Y. Subungual Extraskeletal Chondroma With Finger Nail Deformity: Case Report. J Hand Surg Am. 2010;35(2):296-299.

15. Dumontier C, Abimelec P, Drape JL. Soft-tissue chondroma of the nail bed. Journal of Hand Surgery: British and European Volume. 1997;22(4):474-475.

16. Eun YS, Kim MR, Cho BK, et al. Subungual Soft Tissue Chondroma with Nail Deformity in a Child. Pediatr Dermatol. 2015;32(1):132-134.

17. Enzinger FM. Cartilaginous tumors and tumors like lesions of soft tissues. In: Enzinger FM, editor. Soft Tissue Tumors. USA; 1983. p. 698-718. 